\title{
O AUTOMÓVEL E O DESGASTE SOCIAL
}

Tatiana Schor

Economista, mestre em Geografia Humana, FFLCH-USP

É impressionante a rapidez com que a vida mudou nos dois últimos séculos. As novas tecnologias, como a luz elétrica e o automóvel, marcaram profundamente a maneira de viver das pessoas. Realizou-se e realiza-se continuamente uma "revolução invisível" (Le Goff, 1992). Revolução no sentido de que a vida, seu ritmo, as noções de tempo e de espaço vão mudando completamente. Invisível pelo fato de que estas técnicas entram de uma maneira sutil e impositiva em nossos cotidianos, em um movimento no qual tudo agora parece indispensável. O desenvolvimento técnico redefine, a cada passo, as necessidades sociais.

A luz elétrica é um bom exemplo desta "revolução invisível": o ato de acender a luz resume-se hoje a um simples apertar de botão e, como se fosse mágica, o ambiente se ilumina. O longo processo histórico de iluminar o ambiente, iniciado com o fogo, ficou reduzido a um simples ato não distinguível do próprio entrar no ambiente. Este ato simples encobre e suprime vários gestos e práticas sociais, tal como acender o lampião e, evidentemente, cria outros. Hoje o diferente, o esquisito, é estar em um lugar onde a energia elétrica ainda não invadiu o modo de viver e o ato de iluminar o ambiente é consciente. O normal, o natural, é a não necessidade de consciência dos atos, é quase como se fosse da essência humana viver em um ambiente iluminado.

O automóvel é outro importante exemplo. Para muitas pessoas, imaginar o mundo sem esta máquina é impossível. Trata-se já de uma necessidade social. Tal como no caso da luz elétrica, a utilização do automóvel vai levando ao esquecimento as formas anteriores de locomoção; hoje, conside- rando o processo crescente de urbanização, é provável que mais gente saiba ligar um carro do que arrear um cavalo. $\mathrm{O}$ gesto de ligar o automóvel é mais simples do que o de arrear o cavalo, apesar do fato de compreendermos melhor o funcionamento da locomoção a cavalo que o de um cada vez mais complicado motor de carro (o mesmo pode ser dito para a luz: é mais fácil acender a luz elétrica do que o fogo, mas o funcionamento do fogo é de mais fácil compreensão do que a geração, distribuição e fornecimento da rede elétrica). Por isso, podemos chamar de invisível o processo que revoluciona os atos e desencadeia inúmeros efeitos sucessivos - pelo fato de que o ato mais simples esconde um funcionamento mais complexo. É neste processo que o sonho (da simplificação da vida) e o desejo (de consumo) tornamse uma necessidade.

A sutileza e a rapidez com que esta "revolução invisível" entrou e modificou a maneira de viver, transformando os desejos em necessidades, fazem com que o processo histórico que trouxe à realidade esta revolução também se transforme em algo não visível. A existência cotidiana é de tal maneira determinada por estas técnicas que a história da constituição desta vida cotidiana parece ter como ponto de partida as próprias técnicas que a modificaram. Por isso, deve-se analisar criticamente a utilização destas técnicas e as modificações sociais que ocorreram nesse processo e que as fizeram penetrar na vida. Porém, a possibilidade de uma abordagem crítica só se dá no momento em que o limite da técnica vem à tona, tornando visível o que até então era invisível.

Esta visibilidade dos limites da utilização do objeto técnico ocorre quando ele deixa de ser um apoio ao de- 
senrolar da vida, passando a ser um entrave. Entrave esse que começamos a observar, por exemplo, com o uso do automóvel na cidade de São Paulo. Esta visibilidade vem do fato de que seu uso como meio de transporte, como objeto técnico, está cada vez mais travado, pois o crescente número de congestionamentos impede seu funcionamento. Como algo natural e orgânico, o automóvel passa a ser vivido como um problema, gerando desconforto e mal-estar, e deixando de ser invisível para tornar-se insuportavelmente visível.

O uso do automóvel como objeto técnico, como meio de transporte, não é questionado, pois como uso individual, como máquina, é um desenvolvimento oriundo da necessidade social de locomoção. O problema se revela então como uma especificidade urbana, resultado da escassez, da falta de estruturas para seu funcionamento. Esta compreensão se dá pelo fato de que o uso individual de tal máquina, diferentemente de outras, se realiza em público. O consumo do automóvel como mercadoria só pode ocorrer nas ruas, na esfera pública ${ }^{1}$ da vida e é por isto que seu uso social, como objeto técnico determinante da vida cotidiana, não é neutro, mas carrega consigo e revela muitas das contradições até então invisíveis.

Analisar como a invisibilidade da técnica penetrou a vida modificando profundamente a maneira de viver e por quê, em um determinado momento, as contradições deste processo passam a ser visíveis é um passo importante para a compreensão do desgaste social que experimentamos. O automóvel é um objeto privilegiado para esta análise, pelo fato, já mencionado, de que seu uso (seu consumo propriamente dito, ao contrário do consumo da maioria das mercadorias) é realizado necessariamente na esfera pública. É através da dificuldade que se antepõe à realização da locomoção que este problema - a contradição inerente à mercadoria automóvel - é manifesta na cidade de São Paulo. Como consumo público, revela socialmente a contradição inerente à mercadoria: o consumo individual de uma mercadoria é sua "positividade", mas o consumo social expressa a "negatividade" inerente à mercadoria (basta lembrar, por exemplo, da questão do lixo). O uso do automóvel como consumo individual de um objeto técnico, como meio de transporte, é "positivo", mas como meio social de transporte passa a portar elementos de "negatividade", como a exclusão da possibilidade de uso (a generalização universal do uso do automóvel é a negação interna a esta mercadoria, pois se todos tivessem um carro e resolvessem consumi-lo ao mesmo tempo, este consumo não se realizaria para ninguém). Assim, no li- mite, o consumo do automóvel é também a exclusão de consumo. Em uma sociedade estruturada pelo consumo (ou pela possibilidade de), a exclusão deste ato implica necessariamente a exclusão de um conjunto de relações, que podem gerar um desgaste social expresso na violência e no mal-estar experimentados cotidianamente. Vivemos em uma sociedade na qual as pessoas se reconhecem como iguais (ou diferentes) pelas coisas que têm. Aqueles que se vestem com roupas do mesmo tipo, usam sapatos da mesma marca, dirigem carros de valores iguais reconhecem-se como pares. Como prega Roberto Carlos, na clássica canção Nas curvas da estrada de Santos: "Se você pretende saber quem eu sou, eu posso lhe dizer: entre no meu carro, e na estrada de Santos você vai me conhecer..."

Neste processo de identificação do igual pelos objetos o automóvel tem um papel especial. Isto porque o sistema automobilístico, ${ }^{2}$ tanto pela estandardização de determinadas estruturas urbanas, ${ }^{3}$ necessária para sua realização, quanto pelo significado do próprio objeto em questão, traz consigo a modernização direcionada pela forma mercadoria. Esta modernização se apresenta, entre várias maneiras, como homogeneizadora de práticas sociais, pois trata-se de um complexo sistema produtor de mercadorias que, juntamente com uma de suas mercadorias mais impositivas - o automóvel -, a partir da mercadoria-síntese - o dinheiro - , atingiu seu objetivo produzindo "uma rede social cuja a trama abarca sem lacunas a terra inteira" (Kurz, 1997a:53), ou o One World. Estamos interessados nas práticas sociais relacionadas com o automóvel, pois consideramos que esta mercadoria teve, e continua tendo, um papel importante neste processo de modernização que, a nosso ver, encontra seu fim representado hoje no desgaste da sociedade modernizada desta forma.

Uma maneira de compreender melhor o colapso deste processo que hoje verificamos através da violência é analisar o processo de modernização que culminou neste desgaste, tendo como fio da meada o automóvel: objeto do desejo e materialização do desgaste. Para tanto, é essencial discutir essa mercadoria específica dentro do contexto da modernização e de sua intrincada relação com a sociedade que surge desta determinada configuração, isto é, as práticas e significados sociais que se materializam pelo automóvel.

O surgimento do automóvel está relacionado, de um lado, à acumulação de conhecimentos sociais e, de outro, à necessidade objetiva de melhoria das condições de locomoção, levando em conta a concentração urbana. Esta 
mercadoria, tal como o tear mecânico, a máquina a vapor, a geladeira, o computador, teve e continua tendo um papel importante na transformação da paisagem e das relações sociais.

Com o advento do automóvel e sua generalização ampliam-se as possibilidades de locomoção. Este é, sem dúvida nenhuma, um aspecto importante que diz respeito tanto à individualidade quanto à sociabilidade do homem, visto que redefine, de certa forma, a autonomia em relação ao tempo e principalmente ao espaço, ao desencadear uma forma de apropriação mais efetiva destes pela locomoção. Porém, ao mesmo tempo que se dá a apropriação, acontece o inverso; este tempo e este espaço tornam-se estranhos aos outros momentos da vida.

O tempo transforma-se em velocidade, em quilômetros por hora, e o espaço em simples meio: meio para circulação, para locomoção. Mas isso não acontece simplesmente por causa deste objeto técnico. É claro que ele possibilita tais formas de alienação, mas, por si só, não aliena. A questão não é do conteúdo da técnica, e sim da forma que esta assume na modernidade: a de mercadoria. Para compreendermos como atua este objeto técnico nessa direção é necessário analisar a sociedade contemporânea e as determinações que levam a esta forma de atuação.

Considerando que vivemos em uma sociedade urbana (Léfèbvre, 1991), resultante de uma urbanização quase completa, na qual as relações sociais se dão tendencialmente de uma maneira indireta, monetarizadas, abstratas e burocratizadas, este tecido urbano pode ser visto como um conjunto de manifestações do predomínio do sistema produtor de mercadorias sobre qualquer outra forma social de universalidade abstrata. ${ }^{4}$ Esta urbanização completa como manifestação real do sistema produtor de mercadorias, que incorpora diferentes temporalidades históricas e traduz-se espacialmente por um desenvolvimento desigual, ainda não chegou no seu limite, e nem sabemos se chegará, pois envolve o complexo processo de modernização, que não é necessariamente sem limites. Dado um limite à modernização, não saberemos dizer que sentido tomará a urbanização: se será totalizante e prática, ou simulada (eletronicamente), ou ainda se teremos um processo de relações imediatas barbarizadas (violência).

Uma racionalidade burocrática, cujo fim é a valorização e não a vida, ${ }^{5}$ que se objetiva no indivíduo como consumo, medeia as relações sociais contemporâneas. Estas relações diferenciam a sociedade moderna de outro tipo de sociedade religiosa. ${ }^{6}$ Tem-se então na sociedade urba- na uma racionalidade quantificadora que individualiza homogeneizando, não considerando as particularidades dessas sociedades que são envolvidas pelo cidadão.

Esta sociedade tem como fim em si mesmo a valorização objetivada no consumo individual, que, por sua vez, reflete a mesma objetivação na sociedade. Consome-se mais do que se apropria. É um consumo como fim em si, isto é, muitas vezes privilegia o ato da compra ou a propriedade em detrimento da utilidade do objeto a ser consumido. É possível observar na sociedade urbana uma cisão entre apropriação e consumo. O consumo se autonomiza da apropriação inerente a ele, transformando-se em uma simulação do uso que porta outro fim: a ostentação do valor monetário que o objeto comprado representa. Neste sentido, no seu limite, este uso ostentatório transforma-se em consumo do espetáculo da própria sociedade. É o consumo consumindo a si mesmo sem objeto a ser apropriado. Um exemplo quase caricatural desta forma de uso são os colecionadores de Mercedes e Jaguar, que têm mais automóveis na garagem que pessoas na casa. Assim, uma crítica ao consumo simulado é uma crítica ao uso ostentatório.

O espetáculo (Debord, 1992) é o consumo nas suas derivações mais fetichizadas: não há apropriação, apenas contemplação. O automóvel é uma mercadoria que contém em si tanto a apropriação do objeto (sua funcionalidade) quanto seu uso ostentatório, espetacular (suas outras significações). Para podermos analisar o automóvel, com suas determinações relacionadas ao momento histórico atual, é necessário desvendar essa mercadoria em seus matizes e compreender sua relação com o urbano (que é o pano tecido pela modernização).

Esta é uma forma de estudar a sociedade contemporânea, visto que o automóvel é um objeto, ou melhor uma mercadoria, que nasce com a industrialização e se desenvolve no e para o urbano. O desenvolvimento simultâneo da indústria automobilística e do capitalismo se expressa inclusive nos termos utilizados para designar maneiras de organizar a produção (fordismo, pós-fordismo, toyotismo). Foi através da necessidade de constituição do sistema automobilístico que se direcionou boa parte do desenvolvimento industrial e planejamento urbano. Suas necessidades técnicas impulsionaram a indústria; suas necessidades de espaço e de movimento veloz, como é o caso de São Paulo, redimensionaram o desenho do urbano. O automóvel, tanto construtor quanto destruidor, encanta o homem.

Por que o automóvel encanta o homem? ${ }^{7}$ A importância de responder esta pergunta reside no fato de que, na 
tentativa de entender uma das esquizofrenias do sistema, cria-se no mínimo uma aproximação crítica com a realidade. Talvez seja através da análise de algumas mercadorias, neste caso da mercadoria automóvel, que apareça algum caminho para uma melhor compreensão do núcleo duro (hard core $)^{8}$ da modernidade, o que seria um passo para a mudança.

Para que isso aconteça, é necessário, em primeiro lugar, fazer um esforço teórico para entender o significado do automóvel, que, para nós, exige, antes de mais nada, que se perceba a maneira como esta mercadoria se insere na cotidianidade. ${ }^{9} \mathrm{O}$ automóvel como mercadoria condensa em si, como a própria palavra diz, duas propriedades fundamentais da sociedade moderna: ser auto e mover-se.

O automóvel é uma propriedade privada, individual e móvel. Pode-se dizer, o supra-sumo de uma mercadoria. Um dos aspectos mais importantes do automóvel, que o singulariza em relação a todas as outras mercadorias, é o tipo de propriedade que ele representa e a maneira de usálo,ou seja, a propriedade privada, individual e móvel. Neste sentido, pode ser analisado como símbolo da modernização, considerada como um processo que, tendencialmente, individualiza e transforma tudo em dinheiro. O processo de modernização instrumentaliza, para tanto, todo o conjunto de relações sociais que caem nos nexos da valorização. Já o uso do automóvel propriamente dito, seu consumo efetivo, se realiza na esfera pública e não no âmbito privado e como tal participa da espetacularização da sociedade. É, sem dúvida, o produto perfeito para uma socialização individualizada, pois "liberta" o indivíduo dos constrangimentos sociais do transporte coletivo, tais como de respeitar horários e conviver com outros indivíduos e, ao mesmo tempo, mostra-o, pelo automóvel, como diferente.

A propriedade privada desenvolve-se em todos os seus termos na sociedade capitalista, pois é só nela que todos os objetos e aspectos da vida transformam-se em mercadoria. É por estas características que o automóvel é tão importante para o desenvolvimento do capitalismo e para a inserção da modernidade nos mais remotos cantos do mundo. Se pensarmos que existe tecnologia para carros mais adaptados ao meio urbano (menores, com materiais recicláveis, elétricos, etc.), como também tecnologia de transporte coletivo eficiente e, em alguns lugares, até mesmo "vontade política" de promover o transporte coletivo, como entender esse reino do carro? Como compreender essa necessidade de ter um carro cada vez maior para se conseguir estacionar cada vez menos e cada vez mais veloz para se locomover mais devagar? Onde está o sentido?

$\mathrm{O}$ sentido tem de estar na vida. Então é esta vida que tem de ser compreendida, o quanto ela está deturpada, pois tem como fim outra coisa que não ela mesma, mas a valorização, o consumo, o dinheiro. Logo, é só através do estudo desta deturpação que poderemos compreendê-la na sua forma existente. ${ }^{10}$

A necessidade social de locomoção não é nova e vai além das possibilidades dadas pelas pernas e braços dos homens - fato que se observa historicamente na domesticação do cavalo, elefante e outros animais, no faraó carregado por seus escravos, na canoa, no barco, na charrete e assim por diante. Talvez a explicação do encantamento com o carro venha daí, da necessidade humana de mobilidade, que culmina na mercadoria automóvel e no desenvolvimento do sistema automobilístico. Ainda uma vez, lembremo-nos que o consumo do automóvel, ao contrário do das outras mercadorias, se realiza na esfera pública - o que o tornou um objeto semiprivado e semipúblico. É neste sentido que podemos dizer que o automóvel se desenvolve no urbano. Além dessa diferença particular, e importante, o automóvel, como mercadoria, comporta mistérios. É uma representação de poder, status, de tipo de pessoa. ${ }^{11}$ No limite, o automóvel simboliza todas as necessidades de representação do homem. Afinal: "se você pretende saber quem eu sou, eu posso lhe dizer: entre no meu carro..."

Esta é a particularidade do automóvel, o fato de seu consumo privado se dar na esfera pública, que cria a necessidade de estudá-lo por meio da vida imediata, isto é, por meio de uma análise da vida cotidiana a partir da inserção do automóvel na cotidianidade, visando com isso analisar o seu papel na modernização.

Como temos discutido, o processo de modernização leva a uma homogeneização das práticas sociais (incluídas as relações e estruturas sociais) através da mercantilização de todos os objetos e momentos da vida, construindo assim o One World. Não é simplesmente um processo de homogeneização, mas também um processo de individualização. É a constituição do indivíduo liberto das relações pessoais de parentesco, de religião, e liberto também da terra e dos meios de produção, ${ }^{12}$ é a constituição do indivíduo mônada-dinheiro no sentido de que ele se relaciona com o outro e com a natureza através da forma mercadoria, pelas mercadorias e pelo dinheiro.

Este processo de modernização, muitas vezes chamado de processo de civilização, está relacionado com uma 
suposta "auto-regulação adquirida" (Elias, 1995:9), pois aparece como regulada pelo indivíduo. Porém, a regulação é externa a ele, mônada-dinheiro, que não percebe a totalidade social a não ser em suas esferas separadas (economia, política, educação, público, privado, etc.). As transformações nos meios de transporte e, especificamente, o automóvel, com suas novas práticas e necessidades sociais, é um dos elementos que carrega consigo este processo modernizador (civilizador), ${ }^{13}$ pois é através dele que se generaliza, junto com a mercadoria, uma forma de conduta social (o como guiar e se comportar no volante, por exemplo). Neste sentido, o "learning process" (Elias, 1995:15) necessário a esta auto-regulação é imposto pelo capital.

Devemos apontar que este "learning process" faz parte da idéia e do fato de que em algumas sociedades os motoristas não estão adaptados à era do automóvel, o que exige a implementação de programas de educação de trânsito pelos governos. Este "processo de aprendizagem" não é nem um pouco pacífico. Ao contrário, a da modernização, neste caso a modernização pelo automóvel, implica em morte ${ }^{14}$ (a Cruz Vermelha que estima que $70 \%$ das mortes relacionadas a acidentes automobilísticos ocorrem nos países em desenvolvimento).

O automóvel e o sistema automobilístico são uma das possíveis formas de territorialização deste processo, pois homogeneizam não só as relações sociais, mas também o espaço e o tempo pela potência da máquina e pela estandardização dos signos e práticas relacionadas ao sistema que o automóvel cria. A mercadoria automóvel caracteriza-se por individualizar o uso. O deslocamento é auto(móvel).

Além disso, os limites do consumo desta mercadoria parecem representar muito bem os limites do processo de modernização. Explicando melhor, ao mesmo tempo que este meio de transporte possibilita um passo no processo civilizatório, visto que diminui as distâncias no mundo e o integra, é também um processo de-civilizatório, pois é uma das maiores causas de mortes (violentas) deste final de século. ${ }^{15}$ Pode-se pensar na existência de um limite ao processo civilizatório, que é também um limite ao próprio processo de modernização. Para melhor compreender este limite, basta levarmos em conta as características principais do processo de modernização aqui analisados: quanto mais individualizada e homogeneizada a sociedade, maior aparenta ser a supremacia do indivíduo com relação ao coletivo; porém, se notarmos bem, ocorre exatamente o contrário, ou seja, quanto mais individuali- zada a sociedade, maior a necessidade do coletivo, mesmo que de uma forma negativa e inconsciente. Ninguém mais produz para o seu próprio consumo, mas cada um sente-se completamente liberto das relações sociais que não as do mercado (onde tudo pode ser trocado por dinheiro); e quanto mais homogeneizada a sociedade, mais busca-se o diferente, o único. Essa negação do processo é bem exemplificada nos novos grupos sociais que estão se formando nas últimas décadas, como clubbers, freaks, hippies, neo-hippies, heavy metals, skinheads, neonazistas, entre outros, que travam violentos combates entre si.

Os indivíduos estão de tal forma socializados (abstratamente) que tanto a produção material quanto de suas relações ocorrerem em qualquer lugar do mundo, ao mesmo tempo e relacionados. Pode-se produzir o mesmo automóvel no Brasil ou na Alemanha, pode-se montar um carro em um determinado lugar com todas suas peças tendo sido produzidas em outros lugares (como por exemplo os carros Mondeo e Palio), instituem-se formas de coerção social que não são mais específicas de uma determinada sociedade, mas que estão generalizadas no mundo inteiro, tais como as multas de trânsito, que além da forma de coerção, as máquinas são as mesmas (umas tecnologicamente mais avançadas, outras nem tanto) em todos os países. ${ }^{16}$

Este automóvel do One World é, aparentemente, cada vez mais individual, pois o indivíduo o consome, ainda que em público, no coletivo; tem-se, portanto, o mesmo entrave que o processo de modernização: quanto mais o indivíduo quer utilizar seu carro, menos ele consegue, pois se todos tiverem um carro e quiserem consumi-lo ao mesmo tempo, concretizando a individualidade, se terá o estacionamento forçado (a trava). Quanto mais iguais forem os carros, maiores serão as tentativas de modificar as aparências, tornando cada um único, porém iguais. No primeiro caso, poderemos considerar como sendo o limite da propriedade privada, e no segundo como o limite desta sociedade que se transforma crescentemente em espetacular, isto é, puramente voltada para as aparências.

O automóvel como representante fiel do capital, materializado na lógica de ocupação do solo, se objetiva socialmente nos lugares, principalmente nas grandes metrópoles. O automóvel não só ocupa o espaço e o tempo da sociedade moderna, mas também penetra nas profundezas da vida cotidiana. A vida de qualquer morador de um centro urbano, podendo ser este centro urbano uma metrópole ou uma pequena cidade, é cada vez mais submetida à lógica do automóvel. Seja no seu estresse no trân- 
sito, seja na sua dificuldade de locomoção, seja no barulho ou na paisagem que o envolve, até o não-uso é determinado pela necessidade de uso. O automóvel, tenha o indivíduo consciência ou não, faz parte de seu vivido e de seu imaginário.

O significado da penetração do automóvel em todas as esferas da vida é que o processo de modernização chegou a todos os pontos terrestres: é, como insistimos, o One World. É muito difícil pensar o século XX sem a presença marcante desta mercadoria. Assim, o capitalismo como momento do processo de modernização no qual domina a esfera econômica pode, mais especificamente, ser considerado como automobilístico. Isso porque o automóvel propriamente dito surgiu com o capitalismo; neste sentido, poderíamos falar em "capitalismo automobilístico" (Kurz, 1996).

A esfera dominante no capitalismo é a econômica, é a posição plena do capital. Assim, quando se especifica o capitalismo como sendo automobilístico, tem-se uma especificidade na esfera dominante. Seria como pensar que o aspecto que domina essa esfera fosse o automóvel. O automobilístico, neste sentido, seria dado pela lógica econômica do automóvel, que inclui a indústria, a reconfiguração do urbano, tendo em vista sua necessidade de mobilidade (o uso), de estacionamento, de manutenção e o consumo propriamente dito da mercadoria. Além disso, é interessante notar que o termo capitalismo aceita o adjetivo de automobilístico, e nenhum outro. Este fato se dá pelo aspecto misterioso das mercadorias e do automóvel em especial. O automóvel, como insistimos, tem seu consumo realizado na esfera pública, e é assim que seus mistérios se realizam: ninguém liga para a marca de geladeira que tem em casa, mas a marca de carro funciona como cartão de visita.

Esta é uma maneira muito interessante de caracterizar este período, como capitalismo automobilístico, pois tanto o processo produtivo quanto a organização social (o espaço e o tempo) estão intimamente ligados ao desenvolvimento desta mercadoria e a sua perfeita adaptabilidade ao homem que vive esta forma de socialização.

A socialização que se observa na modernização é uma socialização individualizada e, em certo sentido, homogeneizada. O núcleo desta socialização é o "auto", isto é, o indivíduo atomizado que vive sua relação com a sociedade, quando pensa uma relação social como somatório de relações individuais que se realizam via mercadorias e, mais especificamente, pela mercadoria particular: o dinheiro. Mas, o dinheiro é homogêneo e só é compará- vel pela quantidade, enquanto as outras mercadorias carregam consigo outros elementos e sentidos.

O indivíduo-átomo se vangloria de sua quantidade de dinheiro através das mercadorias que pode comprar e expor. Por isso, as relações sociais são coisificadas. As relações e os processos não significam só o dinheiro, mas quantidade de dinheiro expressa nas mercadorias. Estas mercadorias comportam outra utilidade, além da de expressarem quantidade de dinheiro. Seria como uma apresentação dissimulada da quantidade de dinheiro em uma qualidade de uso (o que estamos chamando de consumo ostentatório). O automóvel, em particular, encaixa-se perfeitamente nesta forma de relação social. Pois, antes de mais nada, o automóvel é auto, expressa a quantidade de dinheiro em uma qualidade específica, representa esta atomização da sociedade e moldura o aparecer. ${ }^{17}$

Podemos então falar de uma "cultura" 18 automotiva? Sim, pelo fato das relações derivadas do uso do automóvel impregnarem, de determinada maneira, o jeito de ser do homem modernizado: eles se reconhecem pelo carro que têm e nem imaginam como seriam suas vidas sem "Ele". Com este objeto, esta prática social torna-se inconsciente, a-histórica, naturalizada e individualizada.

O processo de modernização (automobilística), que põe o automóvel como meio de transporte eficiente e, ao mesmo tempo, nega seu uso criando outras determinações, penetrando a sociedade pelas suas bases, modificando o urbano e o cotidiano, possibilita o surgimento de uma cultura automotiva, que, por sua vez, reforça a modernização automobilística como prática homogeneizadora, constituindo assim um dos elementos do One World.

Podemos então considerar que a análise da cultura automotiva é mais uma maneira de se captar a modernização automobilística nas subjetividades objetivadas nas práticas sociais. Este objeto é retratado não só na música brasileira, mas também na literatura, no cinema e em algumas montagens teatrais. O automóvel é apresentado neste conjunto de manifestações artísticas de diversas maneiras, não só como objeto, mas também como metáfora. A expressão "sinal fechado"19 incorpora-se à linguagem cotidiana. Neste sentido, podemos dizer que as práticas sociais relacionadas com o automóvel (tendo o indivíduo a propriedade de tal objeto ou não) passam a integrar diversos momentos da sociedade. Podemos assim considerar que no interior da cultura moderna surgem elementos de uma "cultura" automobilística, independentemente da relação de propriedade com o automóvel. Afinal, trata-se de uma modernização automobilística. 
O uso do automóvel é uma forma de propriedade individualizada (auto), e por isso tão bem adaptada a esta forma social. Ele possibilita ainda a liberdade como gozo, como prazer. Talvez seja a partir desta constatação que possamos compreender por que o automóvel encanta o homem, apesar da problemática envolvida na sua utilização social. Lembremos que se todo indivíduo fizer uso do automóvel, este uso não será realizável - negando-se, então, como utilidade. Daí nosso interesse, neste momento, estar voltado à questão da velocidade, implícita não só nos anúncios de automóvel, mas também nas manifestações referentes à "cultura automotiva". Pois é a não possibilidade de velocidade, ou melhor, o automóvel parado, estanque em enormes congestionamentos, que gera um dos principais elementos de mal-estar e desgaste na sociedade urbana.

Admita-se, a princípio, que este apelo à velocidade está diretamente relacionado ao apelo de liberdade, pois se não estiver negada (o automóvel parado em um congestionamento) é a velocidade que gera a sensação de liberdade.

Percebe-se que a velocidade transmite uma sensação de liberdade ao homem preso ao sistema. A transformação do ato de deslocamento em velocidade de deslocamento já é uma maneira moderna, capitalista, de pensar, pois passa pela economia de tempo. A velocidade nada mais é que uma relação de espaço sobre tempo. Assim, quanto mais otimizada esta relação, isto é, quanto maior a velocidade, menor o tempo gasto com o deslocamento, melhor para o mônada-dinheiro, pois tempo é dinheiro: poupa-se tempo, poupa-se dinheiro (objetivo final da vida). Essa necessidade de tudo ser cada vez mais veloz aparece também nas publicidades de computadores e no incentivo ao uso da Internet: a velocidade é poder (Virílio, 1977) e poder é, no limite, liberdade absoluta.

É interessante perceber, através do estudo das publicidades do automóvel, como ele é um símbolo social de liberdade. ${ }^{20} \mathrm{O}$ automóvel também pode ser analisado como uma concretização de um desejo de liberdade que vai além da liberdade formal: ${ }^{21}$ é fundamentalmente o desejo de ser livre ${ }^{22}$ que encontra sua expressão no consumo de uma mercadoria que facilita a locomoção. $\mathrm{O}$ do significado do ser livre restringido à liberdade para o consumo.

Analisar a noção de liberdade como liberdade para o consumo - através da inversão da finalidade objetiva que não só a produção sofre no sistema capitalista, mas também a vida sofre na modernização (automobilística) - nos aponta elementos que possibilitam a compreensão do encantamento pelas mercadorias em geral e o automóvel em particular. Interpretamos que no universo das qualidades das mercadorias subjugadas ao seu valor de troca reside a possibilidade de realização, pelo uso, de determinados desejos, tal como o de liberdade. Estes desejos estão certamente latentes nas relações cotidianas do capitalismo. Porém, considerando o fato da publicidade do automóvel apelar constantemente para tais desejos, podemos inferir que existe uma possibilidade de posição subjetiva deles (os desejos) no uso desta mercadoria ainda, que negativamente (restrita à utilidade da coisa) e como caricatura de liberdade. ${ }^{23}$ Neste sentido, o consumo da mercadoria automóvel permitiria de alguma forma a realização desses desejos pressupostos, porém negativamente através do consumo como fim em si e não no uso, como meio de realização de tais desejos.

É a necessidade de ir além da liberdade formal que se submete a uma liberdade de ir e vir individual como única forma de realização do desejo de ser livre. Esta é a razão pela qual o automóvel encanta o homem e torna tão difícil conter o uso desta forma de locomoção (individual). Este fato pode ser claramente percebido na rejeição ao rodízio estabelecido tanto em São Paulo quanto em outras cidades: restringir o uso do automóvel implica restringir a única sensação de liberdade para além da liberdade formal; e é esta a dificuldade de superação tanto do automóvel como meio de transporte, quanto da modernização, pois é nos objetos produzidos por esta modernização, as mercadorias a serem consumidas, que se mostram as formas de satisfação, mesmo que ilusórias, do desejo de ser livre.

Encontra-se na análise da vida cotidiana ${ }^{24}$ uma diversidade de maneiras pela qual o automóvel condiciona a vida, fato que fica claro especialmente com relação à configuração da vida de pessoas que efetivamente possuem automóveis. Mas como fica esse condicionamento para aqueles que não têm essa mercadoria e que estão mais que perversamente livres, pois são indivíduos livres em uma sociedade voltada para o consumo sem a possibilidade de ter nem mesmo a liberdade caricatural proporcionada pelas mercadorias?

Consideremos a história da constituição do indivíduo no processo de modernização. O processo de modernização a partir do feudalismo tem como tendência a individualização social: é a constituição do indivíduo como mônada-dinheiro no sentido de que este indivíduo está livre - da terra, da religião, do senhor feudal e dos meios de produção -, para se constituir em um indivíduo cuja única forma de mediação com a natureza são as merca- 
dorias e o dinheiro, onde seu próprio fazer torna-se mercadoria. Este é o indivíduo mônada-dinheiro, e sua liberdade é a liberdade para o mercado. As antigas culturas agrárias, diferentemente da modernidade, têm o momento religioso como fundamental para reprodução da vida, e é esta religiosidade que provê o nexo da forma social de universalidade abstrata, possibilitando aos indivíduos reconhecerem-se como pares sociais. Já nas sociedades modernas, a universalidade abstrata é determinada pela forma-mercadoria. ${ }^{25}$

O que diferencia a moderna forma social de universalidade abstrata da antiga é que a antiga se realizava de maneira totalizante, enquanto a moderna, que tem como nexo formal a forma-mercadoria, não se manifesta diretamente como uma totalidade, sendo mediada por esferas diferenciadas e aparentemente autônomas entre si. $^{26} \mathrm{Na}$ modernidade, a forma da totalidade (as mercadorias e o dinheiro) aparece como a esfera funcional particular da economia. Neste sentido, o nexo social da universalidade abstrata aparece mediado, indiretamente, pelo mecanismo de mercado.

Dado este processo de transformação da forma social de universalidade abstrata de imediata em mediada (pelas mercadorias e pelo dinheiro), tem-se, ao contrário do que se imagina, um grau elevado de sociabilização, determinado por uma forte separação (as esferas funcionais). Isso acarreta a desconexão entre as pessoas, pois a mediação entre elas e delas com a natureza é a forma-mercadoria. Tem-se uma sociabilização a-social, no sentido de que o nexo é apresentado indiretamente pela mediação do mercado dificultando o reconhecimento de uma totalidade social, mas só a totalidade como esferas separadas (em um momento o "homem econômico", no outro o "homem político", a vida privada separada da vida pública). Este indivíduo sociabilizado asocialmente experimenta a si mesmo como pólo abstrato e inverso à sociedade.

Podemos dizer então que esta sociedade (a-social) fragmentada em esferas refaz (pois necessita dela) sua unidade através das mercadorias e do dinheiro. Contudo, esta unidade é quantificadora e comparativa, e não qualitativa e cooperativa, pois a mercadoria e o dinheiro é que possibilitam todas as mediações sociais. Impõem-se, neste processo, uma forma de sujeito para todas as pessoas, forma esta homogênea, "igualitária" e ditatorialmente presa ao dinheiro. Um sujeito sempre em contraposição a seus outros (objetos), imerso em uma segunda natureza percebida como estranha (outra). Esta unidade quantificadora (a mercadoria e o dinheiro) é o nexo necessário entre este sujeito sujeitado ${ }^{27}$ e a totalidade fragmentada forma de sociabilização a-social, da qual resulta a homogeneização dos mesmos sujeitos sujeitados. Este foi o processo histórico que culminou no capitalismo contemporâneo, na generalização da mercadoria que é, em última análise, o que aqui nos interessa.

Em um país como o Brasil, este processo de fragmentação no capitalismo automobilístico redefine sem cessar modos de vida na direção da conformação do cotidiano moderno. O tempo social totaliza-se num processo que moderniza e generaliza a forma-mercadoria. Ao mesmo tempo mostram-se as travas desse mesmo processo, o desgaste social por elas gerado, ou seja, são os sinais do colapso.

Esta modernização, considerando-a nesse movimento de fragmentação e unidade na troca, ainda está em curso em muitos lugares. O Brasil é um entre os vários países onde ainda não generalizou a troca. A generalização das relações de troca por dinheiro ainda não atingiu todos os lugares nem todas as relações, mas antes dessa fragmentação e unidade na troca conseguir generalizar-se, já podemos observar sinais de seu colapso. É o colapso da modernização no sentido de que é colapso desta forma de mediação social. É a impossibilidade de realização do nexo formal da forma social de universalidade abstrata.

Este é o colapso que observamos no desgaste cotidiano. Podemos observá-lo de maneira direta principalmente na fala de algumas pessoas, aquelas que não têm a propriedade dessa mercadoria e nem imaginam a possibilidade de tê-la. Podemos dizer que mesmo antes de penetrar o universo do consumo, que é o local da tal unidade quantificadora pelo dinheiro, esta possibilidade de sociabilização já se mostra inviável. A fragmentação ocorreu, pois, como expropriados estão sujeitados e livres ${ }^{28}$ necessitando vender seu trabalho para adquirir seu sustento (são mônadas-dinheiro sem dinheiro). Porém, a unidade plena não aconteceu. A fala de um gari ${ }^{29}$ expressa bem esse processo: "Carro é coisa para privilegiado, e nós pobres, quero dizer miseráveis mesmo, não somos e nunca vamos ser privilegiados." A palavra privilegiado, utilizada tanto pelo gari aqui citado quanto nas publicidades de automóveis, indica que podemos considerar a sociedade dividida em dois quase-estamentos: ${ }^{30}$ os que efetivamente fazem parte do universo de consumo (os privilegiados) e os que não fazem parte deste universo (os nãoprivilegiados). Tal como em uma sociedade estamental, a mudança de um estamento para outro é dificílima. Os quase-estamentos que sugerimos separam os que estão unidos mediados pelo dinheiro (mônadas-dinheiro em sua forma 
plena - com dinheiro) e os que estão separados (mônadasdinheiro sem dinheiro). Possivelmente as mônadas-dinheiro sem dinheiro, descoladas do processo, criarão alguma outra forma de relação não mediada pelo dinheiro e pela troca, talvez até uma forma imediata sem necessidade de uma universalidade abstrata.

A vivência cotidiana entre esses quase-estamentos é fonte de medo que invariavelmente transforma-se em malestar e violência, gerando de forma crescente o desgaste social. O problema é saber de que forma se desenvolverá a vivência cotidiana destes dois grupos: haverá mais conflito? Mais violência? Virá a Barbárie $?^{31}$ Ou será pacífica esta convivência? Pouco podemos dizer. Temos de observar analiticamente todas as manifestações do desgaste e suas formas de objetivação na vida cotidiana.

\section{NOTAS}

Este artigo é um desdobramento da Dissertação de Mestrado da autora.

1. Aqui o termo esfera pública é utilizado em contraposição à esfera privada, separação imprescindível para que o processo de modernização se realize plenamente.

2. Gabriel Dupuy (1995) utiliza o termo "système automobile", que traduzimos por sistema automobilístico, para designar o conjunto de elementos que, juntamente com os veículos, asseguram a regularidade dos deslocamentos motorizados homogeneizando o espaço. Utilizaremos o termo no mesmo sentido, enfatizando o termo "sistema", pois é assim, "naturalizados", que aparecem na sociedade o automóvel e seu meio específico.

3. As placas e sinais de trânsito são excelentes exemplos dessa estandardização: os símbolos e cores escolhidas para facilitar a leitura são paradigmas do pensamento moderno, que aprofundam a relação instrumental como meio; "In the apparatus of Western road systems, an absolutely instrumental relationship to the environment is encouraged, and this is particularly true of these signs, not only in their form but in their uniform and ubiquitous placement" (Stallabrass, 1996:119).

4. "O processo de apropriação da natureza, no entanto, enquanto processo humano e social, tem de ser um processo (cegamente pressuposto) de códigos simbólicos. Enquanto a sociedade não toma consciência de si, a essência, em grande parte desligada das programações genéticas, necessita de uma forma social de universalidade abstrata para poder agir como sujeito. A constituição inconsciente de uma semelhante universalidade abstrata pode (segundo Marx) ser qualificada de fetichismo" (Kurz, 1997b:2).

5. Léfèbvre considera a nossa sociedade como sendo uma Sociedade Burocrática de Consumo Dirigido. “'Sociedade Burocrática de Consumo Dirigido', tal é a definição proposta aqui para 'nossa' sociedade. Marcam-se assim tanto o caráter racional dessa sociedade, como também os limites dessa racionalidade (burocrática), o objeto que ela organiza (o consumo no lugar da produção) e o plano para o qual dirige seu esforço a fim de se sentar sobre: o cotidiano" (Léfèbvre, 1992: 68).

6. "Ao contrário das sociedades pré-modernas, o 'processo de troca material com a natureza' não é mais ditado por tradições definidas pela religião, mas pelo processo de abstração da forma-mercadoria: transformação do conteúdo material e sensível da reprodução em 'coisas abstratas', cuja forma fenomênica é o dinheiro indiferente ao conteúdo" (Kurz, 1997b:4).

7. Essa questão está surgindo em vários textos tal como no capítulo "Automobile aesthetics” de Stallabrass (1996:114): “(...) cars are treated by many people with no thing short of love: one man of my acquaintance described his new BMW as the fulfilment of his life, and this devotion is not atypical. So the question is not just pratical but cultural: why are cars so loved?"

8. "... an analysis of capitalism that focuses exclusively on the market and private property can no longer serve as an adequate basis for na emancipatory critical theory" (Postone, 1996:11). O autor considera que para se chegar a esta teoria crítica emancipatória é necessário analisar o núcleo duro da modernidade: a mercadoria e seus fetiches.

9. Define-se, nesse momento, a cotidianidade como sendo o ritmo da vida cotidiana. Léfèbvre (1992) considera que onde há a interação de um lugar com um tempo e com um dispêndio de energia tem-se um ritmo. Cada sociedade tem um ritmo; o cotidiano se estabelece como ritmo, dadas suas exigências de repetição (do tempo e do espaço). Para que haja uma mudança, é necessário que um grupo social intervenha imprimindo um outro ritmo, seja pela força ou não.

10. "Quem quiser saber a verdade acerca da vida imediata tem que investigar sua configuração alienada, investigar os poderes objetivos que determinam a existência individual até o mais recôndito nela" (Adorno, 1993:7).

11. Poderíamos considerar o uso espetacular do automóvel como um valor de uso, que de fato tem uma utilidade, mas é o uso não distinguível de seu fetiche, pois é uso ostentatório que, no limite, significa quantidade de dinheiro disfarçada em funcionalidade.

12. "O prelúdio do revolucionamento, que criou a base do modo de produção capitalista, ocorreu no último terço do século XV e nas primeiras décadas do século XVI. Uma massa de proletários livres como pássaros foi lançada no mercado de trabalho pela dissolução dos séquitos feudais (...)" (Marx, 1988:254).

13. “(...) the transformations in transport since the nineteenth century, is an example of a surprisingly quick breakthrough of humankind into a new dimension, into new modes of social life and, not least, on to a new level of civilization." (Elias, 1995:12).

14. Lembremos da poesia de Adoniran Barbosa : "Iracema, eu nunca mais te vi, Iracema meu grande amor foi embora, chorei, eu chorei de dor porque Iracema meu grande amor foi você. Iracema eu sempre dizia cuidado ao travessá essas rua, eu falava mas você não me escuitava, Iracema você travessô contramão..."

15. Nicholas Faith (1997) mostra que mais pessoas morreram em acidentes automobilísticos que em combate na guerra da Coréia (considerando o mesmo período). Foi no final da guerra contra o Vietnã que o governo dos EUA percebeu que a maioria dos deficientes físicos não eram ex-combatentes, mas sim vítimas de acidentes de automóvel. Este fato levou à intensificação de campanhas de segurança no trânsito. É interessante notar que ultimamente tem aparecido na mídia modelos e atletas deficientes físicos - o que interpretamos como uma manifestação do aumento de acidentes, principalmente automobilísticos, envolvendo jovens.

16. Talvez o sistema de multas seja a concretização do tal processo civilizatório como learning process. São Paulo vem experimentando esta nova forma de modernização desde o começo de 1998, com a introdução do novo código de trânsito: como as multas são muito altas, os motoristas estão começando a respeitar os faróis, as faixas de pedestre e as placas. O engenheiro da CET com o qual conversamos, Max Ernani B. de Paula, afirmou que "nada foi tão eficaz no controle da velocidade como essa fiscalização fotográfica". Segundo ele, uma comparação entre o primeiro semestre de 1998 , no qual a maioria dos pontos de fiscalização já estavam instalados, e o primeiro semestre de 1996, com o novo código de trânsito em vigor, viu-se uma redução de $32 \%$ do número de mortos em acidentes automobilísticos. Além deste importante dado, muitos motoristas ficam raivosos e agridem os "marronzinhos" da CET (fiscais); houve já pelo menos um caso de assassinato. É interessante pensar como este processo civilizatório capital-imposto via multas de trânsito veio a calhar com a dificuldade de financiamento do Estado: será que a tal "indústria de multas" é a nova forma de financiamento?

17. “(...) o automóvel representa o ‘auto', o ‘por si próprio' mecânico de um tipo humano, que apenas desenvolveu a sua liberdade individual para subjugá-la com maior certeza a uma relação mais objetivada e materializada. Assim como os indivíduos somente são avaliados, e se auto-avaliam, segundo seus rendimentos monetários, da mesma forma sua individualidade foi engolida pelas suas próprias criações tecnológicas. Os homens só se reconhecem segundo sua marca de carro (...)" (Kurz, 1997a:352).

18. Este termo "cultura" automotiva encontra justificativa na seguinte afirmação: "Falar em cultura foi sempre contrário à cultura. $\mathrm{O}$ denominador comum 'cultura' já contém virtualmente o levantamento estatístico, a catalogação, a classificação que introduz a cultura no domínio da administração. Só a subsunção industrializada e conseqüente é inteiramente adequada a esse conceito de cultura" (Adorno e Horkeheimer, 1969:123).

19. Esta expressão aparece em muitas músicas, como: "No sinal fechado ele vende chiclete" (Chico Buarque); e "o sinal está fechado para nós que somos jovens" (Belquior).

20. A tentativa de compreender melhor a noção de liberdade conduziu-nos à seguinte formulação, proposta em Ruy Fausto, que tomamos a "liberdade" de ci- 
tar: "No esquema da história que se encontra nos Grundrisse, a passagem da 'pré-história' à 'história' não representa somente o surgimento do homem (sujeito), não concerne somente ao conceito de 'homem'. Tal movimento representa também o surgimento da riqueza (da verdadeira riqueza), da liberdade (da verdadeira liberdade) e, por estranho que pareça, da verdadeira 'propriedade' (ou da 'propriedade individual') no sentido em que a noção é empregada em O Capital, quando Marx escreve: 'Ela (a negação da propriedade capitalista, isto é, o socialismo) restabelece não a propriedade privada, mas sem dúvida a propriedade individual (das individuelle Eigentum), fundada (auf Grundlage) nas aquisições de era capitalista (...)' (A 'propriedade' entedida, conforme o uso nos Grundrisse, como conotando uma relação 'viva', fonte de gozo, entre os homens e as coisas.)"(Fausto, 1983 e 1987:38). Podemos pensar da mesma forma exposta sobre propriedade para a liberdade, como o texto sugere.

21. Estamos considerando liberdade formal como a relação democrática com o Estado e a prática social relacionada ao mercado onde todos são livres para a troca de sua força de trabalho por dinheiro e de dinheiro por mercadorias.

22. Ser livre significa não ser escravo nem de outros homens, nem da religião e nem do dinheiro. Neste último caso, uma liberdade para além do Estado e mercado e, por conseguinte, para além do individualismo, ou melhor, como uma individualidade social (algo ainda não passível de definição, pois é constituída historicamente).

23. "In the shadow of its own incomplete emancipation the bourgeois consciousness must fear to be annulled by a more advanced consciousness; not being the whole freedom, it senses that it can produce only a caricature of freedom - hence its theoretical expansion of its autonomy into a system similar to its own coercive mechanisms" (Adorno, 1997:21).

24. Esta análise está baseada em uma pesquisa de campo que teve como elemento principal o uso do automóvel, realizada em São Paulo durante a elaboração da Dissertação de Mestrado da autora.

25. "A constituição moderna do fetiche não é mais a constituição religiosa da sociedade, mas algo totalmente diverso - a mercadoria e o dinheiro, que são capitalizados 'produtivamente' e promovem assim um novo nexo formal para a universalidade social" (Kurz, 1997b:2).

26. “(...) a totalidade sob a forma-mercadoria tem primeiro de mediar-se consigo mesma através de seu 'tornar-se outro'. (...) Por isso, a mania estrutural de cisão não pode mais estar difusamente dispersa como na constituição religioso prémoderna, mas tem de manifestar-se como separação funcionalista de esferas (entre 'economia' e 'política'), isto é, como separação funcional." Kurz, Robert. O Fim da Política. Teses sobre a crise do sistema de regulação sob a forma-mercadoria. Mimeo, pág.4.

27. "O problema de imposição da nova constituição mercantil do fetiche surge assim, em retrospectiva, como libertação das coações da constituição religiosa, 'como ênfase no igualitarismo e no 'livre-arbítrio'; da perspectiva futura, no entanto, isso se revela como ofuscamento ideológico, pois este novo igualitarismo da forma total do dinheiro não traz somente novas diferenças sociais, uma espécie de miséria tanto mais brutal e o despojamento de todos os meios de produção, mas também novas e não menos brutais coerções" (Kurz, 1997b:10).

28. "Dinheiro e mercadoria, desde o princípio, são tão pouco capital quanto os meios de produção e de subsistência. Eles requerem sua transformação em capital. Mas essa transformação mesma só pode realizar-se em determinadas circunstâncias, que se reduzem ao seguinte: duas espécies bem diferentes de possuidores de mercadorias têm de defrontar-se e entrar em contato; de um lado, possuidores de dinheiro, meios de produção e meios de subsistência, que se propõem a valorizar a soma-valor que possuem mediante compra de força de trabalho alheia; do outro, trabalhadores livres, vendedores da própria força de trabalho e, portanto, vendedores de trabalho. Trabalhadores livres no duplo sentido, porque não pertencem diretamente aos meios de produção, como os escravos, os servos, etc., nem os meios de produção lhes pertencem, como por exemplo, o camponês economicamente autônomo, etc., estando, pelo contrário, livres, soltos e desprovidos deles. Com essa polarização do mercado estão dadas as condições fundamentais da produção capitalista" (Marx, 1988).

29. Entrevista realizada com um gari na cidade de São Paulo durante a elaboração da Dissertação de Mestrado da autora.

30. Pensamos no termo quase-estamento a partir de uma palestra do professor Francisco de Oliveira, realizada no Simpósio Internacional Espaços Públicos e Exclusão Sócio-Espacial. Práticas Urbanas e Inclusão', FAU - USP, 06/11/1998, quando ele considerou que estamos vivendo em uma sociedade de castas que, como tal, tem seus intocáveis, guetos e estamentos. Este fato seria observável nos carros de vidros fechados em contraposição aos meninos de rua (observamos um episódio interessante perto da Av. Nossa Senhora da Paz: um menino pediu dinheiro para um motorista que dirigia uma Mercedes este sinalizando que não abriria o vidro; esse menino veio até nós e disse: "Tia, você viu o cara do carrão? Diz que não tem troco! Até parece, com um baita carrão desses, quem não tem troco somos nós miseráveis!"). O professor considerou que temos o antiespaço público, pois, enquanto sociedade mercantil, não há mais possibilidade de serem estabelecidas relações, tornando-se portanto violentas.

31. Utilizamos o termo barbárie de acordo com Kurz (1997c:43) "Barbárie é obviamente uma metáfora para um acontecimento que ainda não dispõe de um conceito. O termo é de origem eurocêntrica e foi reiteradamente utilizado no contexto de denúncias européias de sociedades não-européias e pré-modernas. Tratava-se, nesse sentido, de destruição de outras culturas. Agora, porém, esse conceito deve ser aplicado à própria formação - nascida em solo europeu - do sistema produtor de mercadorias, e nesse contexto sua aplicação pode ser justificada."

\section{REFERÊNCIAS BIBLIOGRÁFICAS}

ADORNO, T. Minima Moralia. São Paulo, Ática, 1993. Prismes critique de la culture et société. Paris, Payot, 1986. Negative dialectics. New York, Continuum,1996.

DEBORD, G. La société du spectacle. Paris, Ed. Gallimard, 1992.

DUPUY, G. Les territoires de l'automobile. Paris, Collection Villes, Éditions Anthropos, 1995.

ELIAS, N. "Technization and civilization". In: Theory, culture \& society. London, Sage Thousand Oaks and New Delhi, v.12, 1995, p.7-42.

FAITH, N. CRASH. The limits of car safety. Boxtree and Channel Four Television Corporation, Great Britain, 1997.

FAUSTO, R. Marx. Lógica e política. São Paulo, Brasiliense, tomo I (1983), tomo II (1987).

LE GOFF, O. L'invention du confort. Naissance d'une forme sociale. França, Presses Universitaires de Lyon, Lyon, 1992.

KURZ, R. O colapso da modernização. Da derrocada do socialismo de caserna à crise da economia mundial. Rio de Janeiro, Paz e Terra, 1993.

. Luz verde para o caos da crise. Cadernos do Labur. Série Autores Alemães. Laboratório de Geografia Urbana, FFLCH- USP, ano I, n.1, 1996. Os últimos combates. 2a edição, São Paulo, Editora Vozes, 1997a. O fim da política. Teses sobre a crise de regulação sob a formamercadoria. $1997 \mathrm{~b}$, mimeo.

Dominação sem sujeito. Sobre a superação de uma crítica social redutora. $1997 \mathrm{c}$, mimeo.

LÉFÈBVRE, H. Critique de la vie quotidienne, le sens de la marche. Paris, Éditions L' Arche, 1958.

Critique de la vie quotidienne, fondements d'une sociologie de la quotidienneté. Paris, Éditions L’ Arche, Paris, 1961.

. A vida cotidiana no mundo moderno. São Paulo, Ática, 1991.

Élèments de rythmanalyse. Introduction à la connaissance des rythmes. Paris, Editions Syllepse, 1992.

MARX, K. O capital crítica da economia política. São Paulo, Editora Nova Cultural, 1988

POSTONE, M. Time, labor, and social domination. A reinterpretation of Marx's critical theory. England, Cambridge University Press, 1996.

SCHOR, T. O automóvel e a cidade de São Paulo: a territorialização do processo de modernização (e de seu colapso). Dissertação de Mestrado. São Paulo, Departamento de Geografia da FFLCH da Universidade de São Paulo, 1999.

STALLABRASS, J. Gargantua manufactured mass culture. London, Verso, 1996.

VIRÍLIO, P. Velocidade e política. São Paulo, Estação Liberdade, 1977. 